\title{
Pesquisa de interferon gama em tecido periodontal de ratos submetidos à movimentação dentária induzida
}

Daniel Mascarenhas da Silveira*, Fernanda Catharino Menezes Franco**,

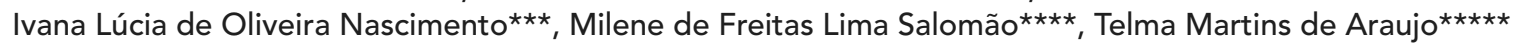

\begin{abstract}
Resumo
Introdução: durante o tratamento ortodôntico, um processo inflamatório é induzido, desencadeando uma série de eventos bioquímicos que resultam na movimentação dentária. Estímulos como a hipóxia e a deformação mecânica são os principais fatores responsáveis pela quebra da homeostasia celular, resultando em estresse e liberação de diversos mediadores importantes para o movimento do dente. Para que a remodelação óssea ocorra durante o tratamento ortodôntico, fatores reguladores, como subprodutos do ácido araquidônico e citocinas, são liberados. Ao interferon gama (INF- $\gamma$ ), uma citocina principal liberada após a indução da resposta imune adaptativa, é atribuída a função de atrair os macrófagos, que auxiliam na remoção de restos celulares e promovem a cicatrização e reorganização das áreas com inflamação. Objetivo: visto que alguns aspectos biológicos que permeiam a movimentação dentária ainda não estão totalmente esclarecidos, procurou-se, neste trabalho, verificar a expressão do INF- $\gamma$ por células do periodonto de ratos submetidos à movimentação ortodôntica. Métodos: a amostra foi constituída por nove ratos, cujos primeiros molares superiores direitos foram movimentados com uma força de $0,5 \mathrm{~N}$, por 3, 7 e 14 dias. Os molares esquerdos desempenharam o papel de grupo controle. Resultados: através da imunohistoquímica, foi verificada a ausência de expressão de INF- $\gamma$ na quase totalidade dos tecidos estudados, tanto no lado de pressão quanto no lado de tração.
\end{abstract}

Palavras-chave: Interferon gama. Movimentação dentária. Imunohistoquímica.

\section{INTRODUÇÃO}

De fundamental importância para o movimento ortodôntico, a remodelação óssea atua removendo a pressão sobre o ligamento periodontal, permitindo o movimento dentário e, consequentemente, dissipando as forças incidentes sobre os dentes. Oriundos dessas forças, os estresses funcional e mecânico induzem a liberação de importantes mediadores para a movimentação dentária ${ }^{6}$.

Para Vandevska-Radunovic ${ }^{16}$, a presença de mediadores inflamatórios pode ser evidenciada em todo tecido periodontal de suporte durante a reação inflamatória produzida pela movimentação ortodôntica. É verificado, também, que os níveis de

* Aluno do Curso de Especialização em Ortodontia e Ortopedia Facial da UFBA.

** Mestre em Ortodontia pela UFRJ.

*** Mestre e doutora em Imunologia pela UFBA.

**** Mestre em Imunologia pela UFBA.

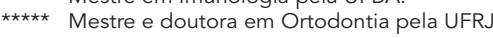


prostaglandina e interleucina-1 (IL-1) aumentam no ligamento periodontal em curto tempo após a aplicação de forças ortodônticas ${ }^{8}$. Além disso, mensageiros bioquímicos, como o óxido nítrico, também surgem durante esse período ${ }^{5}$.

Estudos demonstraram que algumas citocinas estão envolvidas na deposição e reabsorção óssea in vivo e in vitro, como a IL-1, IL-6 e o fator de necrose tumoral $\alpha^{3}$. Sandy, Farndale e Meikle ${ }^{14}$ afirmaram que o tecido conjuntivo pode ser influenciado pelas citocinas, incluindo interleucinas, fatores de necrose tumoral, fatores de crescimento e interferons. Segundo Kuby et al. ${ }^{11}$, o INF- $\gamma$ contribui na resposta inflamatória aguda e principalmente na crônica, atraindo macrófagos e aumentando o número de células fagocitárias no local da inflamação.

Considerando seu potente papel na regulação imunológica, foi sugerido que o INF- $\gamma$ pode estar envolvido na remodelação periodontal durante a movimentação ortodôntica, diferentemente de outras citocinas como a IL-4 e IL-10, não detectadas no lado de pressão durante a movimentação dentária ${ }^{2}$.

Citocinas como INF- $\gamma$ e IL-4 podem suprimir a formação de osteoclastos, por atuarem sobre suas células precursoras - os macrófagos da medula óssea $^{12}$. De acordo com Fox e Chambers ${ }^{7}$, o INF- $\gamma$ evita a formação de osteoclastos por atuar diretamente na diferenciação de suas células progenitoras, levando-as à morte celular.

Kamolmatyakul, Chen e $\mathrm{Li}^{10}$ explicaram que o INF- $\gamma$ pode inibir a reabsorção óssea, por regular os níveis de RNAm da cathepsin $\mathrm{K}$, uma importante protease da reabsorção, e reduzir a produção dessa enzima. Além disso, poderia inibir a formação de osteoclastos em um período precoce de sua diferenciação.

Visto que o papel do INF- $\gamma$ na movimentação dentária ainda não está esclarecido, o presente trabalho, através de um modelo experimental de movimentação dentária, verificou a expressão dessa citocina em secções periodontais durante a movimentação dentária induzida em ratos.

\section{MATERIAL E MÉTODOS}

Animais

Nove ratos machos da linhagem Wistar, com 4045 dias de idade, pesando cerca de $300 \mathrm{~g}$ cada, foram utilizados nesse estudo (aprovado pela resolução $n^{\circ}$ 015/2005 do Comitê de Ética no Uso de Animais das Faculdades Integradas da Bahia). Os animais foram divididos em 3 grupos com 3 ratos cada.

Os primeiros molares superiores direitos de todos os ratos foram movidos mesialmente por meio de um dispositivo construído a partir de um modelo proposto por Heller e Nanda ${ }^{9}$ (Fig. 1A). Para tanto, utilizou-se uma mola fechada de níquel-titânio (Dentaurum, Alemanha) presa com fios de amarrilho ao primeiro molar e ao incisivo superior do mesmo lado (Fig. 1B).

Uma força de $0,5 \mathrm{~N}$, mensurada por um dinamômetro de precisão devidamente calibrado (Dentaurum, 25-250g, nº 04071100), foi aplicada e nenhuma reativação foi realizada durante o período experimental. Os primeiros molares superiores do lado esquerdo dos ratos funcionaram como grupo controle.

Todo o procedimento de instalação do aparelho foi realizado sobre anestesia geral com pentobarbital sódico (Nembutal, Abbott Laboratórios do Brasil Ltda., São Paulo/SP).

Os ratos do grupo 1 foram sacrificados no terceiro dia do experimento, os animais do grupo 2 no sétimo dia e os do grupo 3 no décimo quarto dia de movimentação dentária. A eutanásia foi realizada com uma dose excessiva do anestésico por via intraperitoneal.

Em todos os casos, as maxilas foram imediatamente removidas, dissecadas e seccionadas na sua linha média. A fixação foi realizada em solução de paraformaldeído tamponado a 4\%, por 24 horas. Em seguida, os fragmentos foram descalcificados em solução de EDTA a 10\% para, logo após, serem incluídos em parafina.

Secções sagitais com $5 \mu \mathrm{m}$ de espessura do lado direito e esquerdo de cada rato foram executadas paralelas ao longo eixo dos primeiros molares e 
montadas em lâminas para que se processasse a técnica de imunohistoquímica. Com o propósito de padronizar as secções histológicas e de se utilizar tecidos com maior suscetibilidade aos efeitos de pressão e tração da movimentação dentária, os cortes utilizados foram os mais próximos do sulco central do primeiro molar superior.

As faces mesial e distal da raiz mesial do primeiro molar superior foram escolhidas, respectivamente, como as áreas do lado de pressão e tração a serem avaliadas (Fig. 2).

\section{Imunohistoquímica}

Realizou-se a desparafinização dos cortes com banhos em xilol, seguidos por imersões em álcool absoluto. O bloqueio da peroxidase endógena foi realizado com $\mathrm{H}_{2} \mathrm{O}_{2}$ a $10 \%$ para, em seguida,
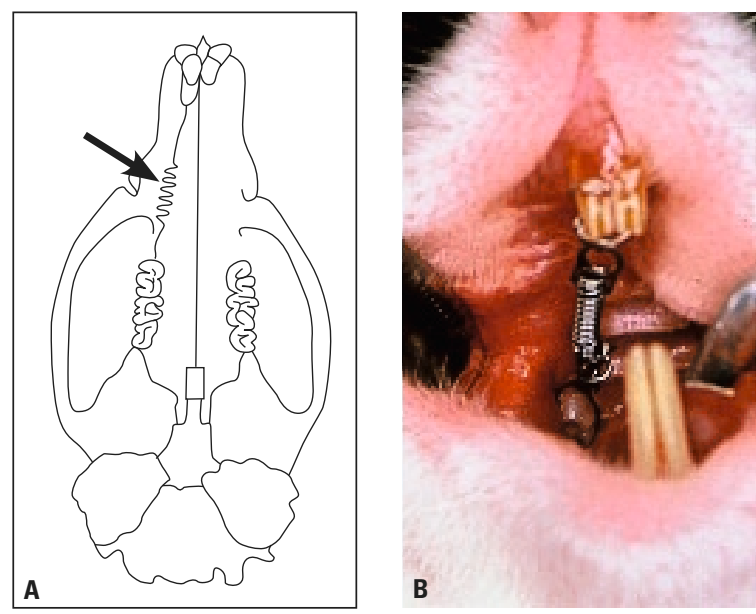

FIGURA 1 - Aparato ortodôntico empregado para movimentação dentária: A) desenho esquemátic $0^{9}$; B) fotografia do aparelho instalado na maxila.

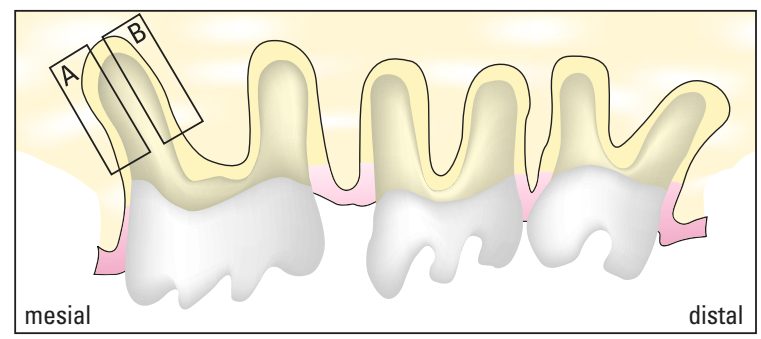

FIGURA 2 - Representação esquemática das áreas periodontais demarcadas para análise microscópica: (A) área de pressão e (B) área de tração da raiz mesial do $1 \mathrm{MS}$. proceder-se à recuperação antigênica por digestão enzimática com tripsina (Sigma Chemical Co., St. Louis, EUA). A inibição das ligações inespecíficas foi realizada com leite em pó desnatado diluído em PBS.

Incubou-se o anticorpo primário (R\&D Systems, EUA) anti-interferon gama de rato na diluição de 1:100, permanecendo durante toda a noite a $4^{\circ} \mathrm{C}$.

$\mathrm{O}$ anticorpo secundário, conjugado com biotina ligante, foi aplicado, seguido pela utilização do complexo streptoavidina-peroxidase (kit Dakocytomaion LSAB + System HRP). Procedeuse a revelação com diaminobenzidina (DAB, Dako, Dinamarca) e contra-coloração com hematoxilina de Harris. Os cortes foram novamente banhados em álcool absoluto e xilol, e as lâminas foram montadas com Entellan (Merck, Alemanha).

\section{Análise microscópica}

As faces mesial e distal da raiz mesial foram eleitas, respectivamente, como as áreas do lado de pressão e tração a serem avaliadas através de microscopia óptica. As mesmas áreas radiculares também foram escolhidas para a análise nos dentes não movimentados.

Às lâminas analisadas foram atribuídos escores de acordo com um padrão estabelecido: 0 = nenhuma célula das áreas avaliadas com positividade para o INF- $\gamma ; 1=$ positividade para o INF- $\gamma$ em menos de $50 \%$ das células das áreas avaliadas; 2 = positividade para o INF- $\gamma$ em mais de $50 \%$ das células das áreas avaliadas.

\section{RESULTADOS}

Após a análise dos cortes, pôde-se constatar que, dos 9 ratos do grupo experimental, apenas 1 espécime de cada grupo (3, 7 e 14 dias) apresentou positividade (células isoladas) para o INF- $\gamma$ (Fig. 3). Quanto ao grupo controle, com a exceção de 1 rato (positividade em células isoladas), nenhum outro espécime estudado apresentou positividade para o INF- $\gamma$ (Fig. 3). Os resultados podem ser verificados nas tabelas de 1 a 6 . 

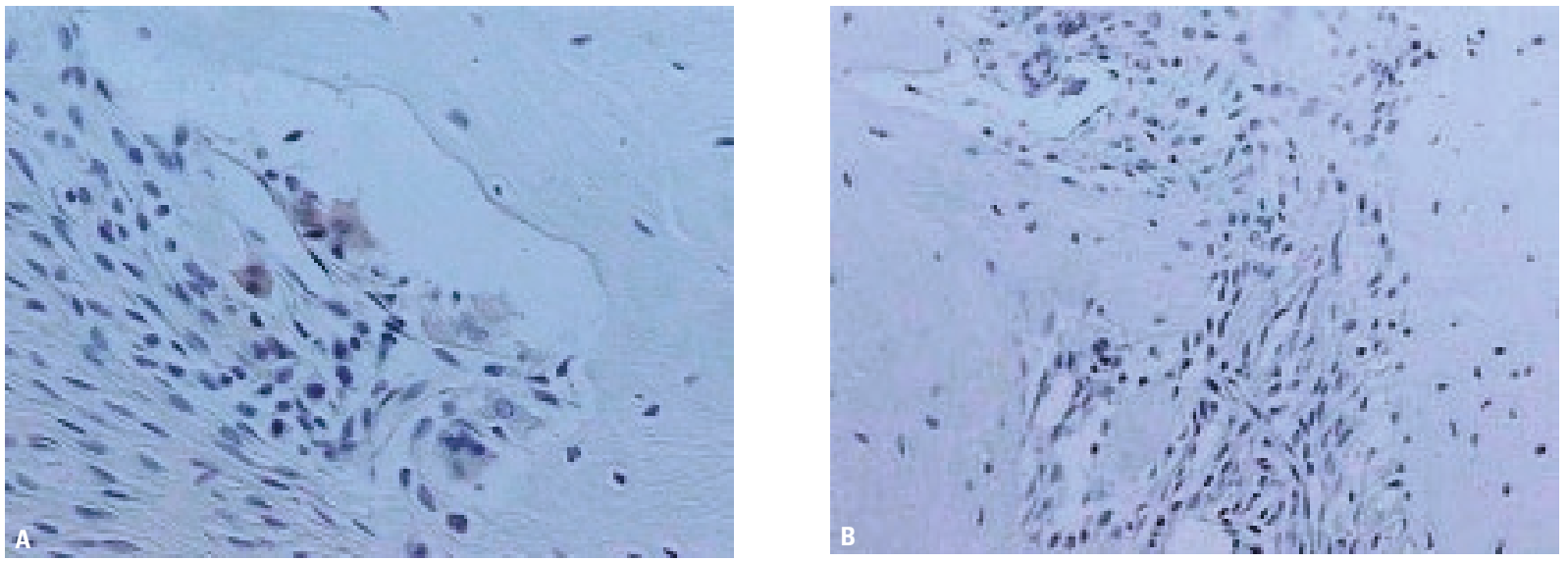

FIGURA 3 - Representação esquemática das áreas periodontais demarcadas para análise microscópica: (A) área de pressão e (B) área de tração da raiz mesial do $1 \mathrm{MS}$.

TABELA 1 - Detecção de INF- $\gamma$ no grupo 1 (3 dias), lado direito (experimental).

\begin{tabular}{|ccc}
\hline grupo 1 - experimental & Iado de pressão & Iado de tração \\
rato 1 & 0 & 0 \\
rato 2 & 1 & 0 \\
rato 3 & 0 & 0 \\
\hline
\end{tabular}

TABELA 3 - Detecção de INF- $\gamma$ no grupo 2 (7 dias), lado direito (experimental).

\begin{tabular}{|ccc|}
\hline grupo 2 - experimental & lado de pressão & lado de tração \\
\hline rato 1 & 0 & 0 \\
rato 2 & 0 & 0 \\
rato 3 & 1 & 0 \\
\hline
\end{tabular}

TABELA 5 - Detecção de INF- $\gamma$ no grupo 3 (14 dias), lado direito (experimental).

\begin{tabular}{|ccc|}
\hline grupo 3 - experimental & lado de pressão & lado de tração \\
\hline rato 1 & 1 & 0 \\
rato 2 & 0 & 0 \\
rato 3 & 0 & 0 \\
\hline
\end{tabular}

\section{DISCUSSÃO}

Neste estudo, com o uso da técnica de imunohistoquímica, foi verificada uma rara expressão de INF- $\gamma$ nos lados de pressão e de tração de todos os grupos estudados (Tab. 1-6). Esses dados sugerem, nos tempos e regiões avaliadas, participação pouco significativa dessa citocina na remodelação
TABELA 2 - Detecção de INF- $\gamma$ no grupo 1 (3 dias), lado esquerdo (controle).

\begin{tabular}{|ccc|}
\hline grupo 1 - controle & lado de pressão & lado de tração \\
\hline rato 1 & 0 & 0 \\
rato 2 & 0 & 0 \\
rato 3 & 0 & 1 \\
\hline
\end{tabular}

TABELA 4 - Detecção de INF- $\gamma$ no grupo 2 (7 dias), lado esquerdo (controle).

\begin{tabular}{|ccc|}
\hline grupo 2 - controle & lado de pressão & lado de tração \\
\hline rato 1 & 0 & 0 \\
rato 2 & 0 & 0 \\
rato 3 & 0 & 0 \\
\hline
\end{tabular}

TABELA 6 - Detecção de INF- $\gamma$ no grupo 3 (14 dias), lado esquerdo (controle).

\begin{tabular}{|ccc} 
grupo 3 - controle & lado de pressão & lado de tração \\
rato 1 & 0 & 0 \\
rato 2 & 0 & 0 \\
rato 3 & 0 & 0 \\
\hline
\end{tabular}

periodontal durante a movimentação dentária induzida em ratos.

Alguns autores $7,10,12$ afirmam que o INF- $\gamma$ poderia suprimir a formação de osteoclastos por atuar em um período precoce de sua diferenciação. Choi e $\mathrm{Kim}^{4}$ reforçaram essa afirmativa, ao assegurarem que o INF- $\gamma$ atuaria diretamente sobre a 
formação dos osteoclastos ou indiretamente, através das células $B$ - quando ativadas na presença de citocinas Thl, como o INF- $\gamma$. Considerando consenso que a presença de osteoclastos é imprescindível para a remodelação óssea, os fatos mencionados consolidam a ideia da pouca participação dessa citocina na movimentação ortodôntica.

Outro aspecto relevante da reabsorção óssea diz respeito à liberação de enzimas, como a cathepsin $\mathrm{K}$, importantes para a degradação da matriz orgânica pelos osteoclastos. Altamente ativa e considerada a principal protease da reabsorção óssea, a cathepsin $\mathrm{K}$ hidrolisa as proteínas da matriz extracelular a um $\mathrm{pH}$ de 5,5 .

Contudo, o INF- $\gamma$ é capaz de atuar diminuindo a transcrição dos níveis de RNAm da cathepsin $\mathrm{K}$, reduzindo a produção dessa enzima e regulando os eventos que envolvem o controle da reabsorção óssea ${ }^{10,15}$. Visto que a movimentação ortodôntica depende, sobretudo, da reabsorção óssea, a influência exercida pelo INF- $\gamma$ sobre a cathepsin K reforça a tese de que essa citocina não é atuante durante a movimentação dentária induzida.

Com relação às células capazes de produzir o INF- $\gamma$, diversos autores ${ }^{1,10,12,13}$ citam o linfócitos T e as células Natural Killers (NK) como responsáveis pela produção dessa citocina. No entanto, essas células são pouco vistas no ligamento periodontal, mesmo em um processo inflamatório provocado pelos estresses mecânico e funcional do movimento ortodôntico. A deformação mecânica das células do ligamento periodontal e a hipóxia gerada pela compressão dos vasos sanguíneos induzem uma resposta imune do tipo inata ou inespecífica, caracterizada pela presença de monócitos, macrófagos e neutrófilos. Diferentemente, a resposta imune adaptativa ou específica é caracterizada pela presença de linfócitos T e B. Essa resposta é altamente específica para determinado patógeno e torna-se mais eficiente a cada contato subsequente com o mesmo agressor. Visto que a inflamação oriunda da movimentação dentária não decorre de patógenos, possivelmente a presença de linfócitos, e consequentemente de
INF- $\gamma$, no ligamento periodontal será escassa durante a movimentação ortodôntica.

Alhashimi et al. $^{2}$ reafirmaram que o INF- $\gamma$ é produzido principalmente pelos linfócitos $\mathrm{T}$ e células NK, no entanto, sugeriram o envolvimento dessa citocina no remodelamento periodontal durante o movimento ortodôntico. Esses autores escolheram, como base de suas investigações, as lâminas com as mais longas zonas hialinizadas de cada espécime. Como, no presente trabalho, as zonas hialinizadas não eram de grande extensão, pode-se alegar, como explicação para os distintos resultados, a diferença na quantidade de hialinização e nos cortes de tecidos analisados.

Kuby et al. ${ }^{11}$ afirmaram que o INF- $\gamma$ pode contribuir na resposta inflamatória aguda, e principalmente na crônica, aumentando o número de células fagocitárias ao atrair os macrófagos para o local da inflamação. Essa capacidade de atração sugere a possibilidade de recrutamento, também, de osteoclastos, um tipo especializado de macrófago, gigante, multinucleado e adaptado para a reabsorção óssea. No entanto, é necessário aprofundar as investigações a respeito do mecanismo de atração e dos tipos de macrófagos influenciados pelo INF- $\gamma$.

\section{CONCLUSÃO}

A presença do INF- $\gamma$ no periodonto de inserção de ratos submetidos à movimentação dentária induzida por períodos de 3, 7 e 14 dias foi pouco verificada. Tal fato sugere reduzida importância dessa citocina como mediador bioquímico atuante na remodelação do periodonto de inserção durante a movimentação dentária.

\section{AGRADECIMENTOS}

Os autores agradecem à Semp Toshiba pelo constante apoio ao Centro de Ortodontia e Ortopedia Facial Prof. José Édimo Soares Martins. 


\title{
Gamma-interferon investigation in rat periodontal tissue under induced dental movement
}

\begin{abstract}
Introduction: During the orthodontic treatment, an inflammatory process is induced, triggering series of biochemical events that results in dental movement. Stimuli such as hypoxia and mechanical deformation are the main factors responsible for the breaking of cell homeostasis, resulting in stress and liberation of several important mediators for tooth movement. To occur osseous remodeling during orthodontic treatments, regulating factors such as sub products of arachidonic acid and cytokines are released. To interferon-gamma (INF- $\gamma$ ), a main cytokine released after induction of adaptive immune response, is attributed the function of attracting the macrophages, which aids in removing cell rests and promote healing and reorganization of the inflamed areas. Aim: Given that some biological aspects that permeate dental movement are not yet fully clear, we aimed in this study to investigate INF- $\gamma$ expression in the periodontium of rats under orthodontic movement. Methods: The sample was composed of 9 rats, whose first upper right molars were moved with a force of $0,5 \mathrm{~N}$, for 3,7 and 14 days. The left molars were used as controls. Results: Through immunohistochemistry, we verified the absence of INF- $\gamma$ expression in almost all the studied tissues, in both the traction and pressure sides.
\end{abstract}

Keywords: Interferon-gamma. Tooth movement. Immunohistochemistry.

\section{REFERÊNCIAS}

1. ABBAS, A. K.; LITCHMAN, A. H.; POBER, J. S. Imunologia celular e molecular. 4. ed. Rio de Janeiro: Revinter, 2003

2. ALHASHIMI, N. et al. Orthodontic movement induces high numbers of cells expressing IFN-gamma at mRNA and protein levels. J. Interferon Cytokine Res., Larchmont, v. 20, no. 1, p. 7-12, Jan. 2000

3. ALHASHIMI, N. et al. Orthodontic tooth movement and de novo synthesis of proinflammatory cytokines. Am. J. Orthod. Dentofacial Orthop., St. Louis, v. 119, no. 3, p. 307-312, Mar 2001.

4. CHOI, Y.; KIM, J. J. B cells activated in the presence of Th1 cytokines inhibit osteoclastogenesis. Exp. Mol. Med., Seoul, v. 35 , no. 5 , p. 385-392, Oct. 2003

5. COLLIN-OSDOBY, P.; NICKOLS, G. A.; OSDOBY, P. Bone cell function regulation and communication: a role for nitric oxide. J. Cell. Biochem., New York, v. 57, p. 399-408, Mar. 1995.

6. CONSOLARO, A. Movimentação dentária induzida: biologia aplicada à prática clínica. In: CONSOLARO, A. Reabsorções dentárias nas especialidades clínicas. 1. ed. Maringá: Dental Press, 2002. p. 221-257.

7. FOX, S. W.; CHAMBERS, T. J. Interferon-gamma directly inhibits TRANCE-induced osteoclastogenesis. Biochem. Biophys. Res. Commun., San Diego, v. 276, no. 3, p. 868-872, Oct. 2000.

8. GRIEVE, W. G.; JOHNSON, G. K.; MOORE, R. N. Prostaglandin-E and interleukin-1 beta levels in gingival crevicular fluid during human orthodontic tooth movement. Am. J. Orthod. Dentofacial Orthop., St. Louis, v. 105, no. 4, p. 369-374, Apr. 1994.

9. HELLER, I. J.; NANDA, R. Effect of metabolic alteration of periodontal fibers on orthodontic tooth movement: an experimental study. Am. J. Orthod. Dentofacial Orthop., St. Louis, v. 75, no. 3, p. 239-258, Mar. 1979

10. KAMOLMATYAKUL, S.; CHEN, W.; LI, Y. P. Interferon-gamma down-regulates gene expression of cathepsin $\mathrm{K}$ in osteoclasts and inhibits osteoclast formation. J. Dent. Res., Alexandria, v. 80 , no. 1, p. 351-355, Jan. 2001.
11. KUBY, J. et al. Immunology. 3rd ed. New York: W. H. Freeman, 1999

12. LACEY, D. L.; ERDMANN, J. M.; TEITELBAUM, S. L. et al. Interleukin 4, interferon-gamma, and prostaglandin E impact the osteoclastic cell-forming potential of murine bone marrow macrophages. Endocrinology, Springfield, v. 136, no. 6, p. 2367-2376, June 1995.

13. PARHAN, P. O sistema imune. 1. ed. Porto Alegre: Artmed, 2001.

14. SANDY, J. R.; FARNDALE, R. W.; MEIKLE, M. C. Recent advances in understanding mechanically induced bone remodeling and their relevance to orthodontic theory and practice. Am. J. Orthod. Dentofacial Orthop., St. Louis, v. 103, no. 3, p. 212-222, Mar. 1993.

15. TROEN, B. R. The role of cathepsin $\mathrm{K}$ in normal bone resorption. Drug News Perspect., Barcelona, v. 17, no. 1, p. 19-28, Jan./Feb. 2004

16. VANDEVSKA-RADUNOVIC, V. Neural modulation of inflammatory reactions in dental tissues incident to orthodontic tooth movement: a review of the literature. Eur. J. Orthod., Oxford, v. 21, no. 3, p. 231-247, June 1999.

\section{Endereço para correspondência}

Telma Martins de Araujo

Av. Araújo Pinho, $627^{\circ}$ Andar

CEP: 40.110-150 - Canela - Salvador / BA

E-mail: ortoufba@ufba.br 